\title{
Hidrostática: Teoria x Prática Experimental, História em quadrinhos - Manual utilizável de Hidrostática para o ensino/aprendizagem em Física
}

\author{
Jacinta S. Silva ${ }^{1}$, Frederico T. Teófilo², Elexlhane Damaceno de Siqueira ${ }^{3}$, Yara G. S. Diniz ${ }^{4}$, Ricardo S. \\ Costa $^{5}$, João B. Diniz ${ }^{6}$ \\ 1, 2,3,5,6 Universidade Federal de Rondônia (UNIR) \\ ${ }^{4}$ Instituto Federal Rondônia (IFRO)
}

Palavras-Chave: Ensino, Experimento, História em Quadrinhos.

\section{Introdução}

As atividades experimentais quando inseridas na grade curricular da escola, sejam elas feitas na sala de aula ou no laboratório são estratégias que podem contribuir para o aprendizado do ensino de Física. Muitos autores têm pesquisado e discutido as atividades experimentais no ensino no Brasil. O produto educacional que pretende-se desenvolver com este projeto caracteriza-se como um conjunto de processos, a saber: avaliação inicial do conteúdo de Hidrostática com aplicação de um questionário objetivo do tema, averiguando os conhecimentos prévios dos alunos sobre o assunto; apresentação dos conceitos de Hidrostática ilustradas em histórias em quadrinhos; desenvolvimento dos experimentos, estes relacionados ao cotidiano e finalizando com uma feira expositiva dos experimentos.

No planejamento dessas atividades experimentais busca-se contemplar experimentos simples que sejam ao mesmo tempo cativantes, que estejam relacionados ao cotidiano dos alunos e desenvolvidos com materiais de baixo custo. As atividades experimentais aplicadas permitem ao aluno fazer conexões entre o experimento e seus conhecimentos prévios estudados na abordagem conceitual para que de fato ocorra aprendizagem significativa, confirmando a fundamentação teórica desse trabalho.

Os Parâmetros Curriculares Nacionais do Ensino Médio (PCN's) afirmam que: "É indispensável que a experimentação esteja sempre presente ao longo de todo o processo de desenvolvimento das competências em Física, privilegiando-se o fazer, manusear, operar, agir, em diferentes formas e níveis".

Para Moreira (2009), a teoria do pesquisador Vygotsky propõe que o desenvolvimento cognitivo se dá por meio da interação social, em que, no mínimo, duas pessoas estão envolvidas ativamente trocando experiência e ideias, gerando novas experiências e conhecimento. A proposta desse trabalho é justamente envolver os alunos nos experimentos sob a perspectiva vygotskiana.

\section{Metodologia e Material}

Os experimentos realizados pelos alunos terão caráter de verificação, visto que inicialmente esses conteúdos estarão presentes nas histórias em quadrinhos e posteriormente serão verificados experimentalmente.

No primeiro momento, será aplicado um questionário sobre o conteúdo de Hidrostática com o intuito de descobrir o grau de conhecimento, ou seja, o conhecimento prévio dos alunos sobre o assunto abordado, posteriormente será apresentado o conteúdo de Hidrostática por meio de história em quadrinhos, relacionando o mesmo com o cotidiano vivenciado pelos alunos.

Para realizar as atividades a turma será conduzida em grupos, nos quais a distribuição deles se dará em níveis diferentes de conhecimentos, onde cada grupo será responsável pela montagem de um experimento específico, abordando os conteúdos: pressão e densidade, pressão atmosférica, princípio de Pascal, lei de Stevin e princípio de Arquimedes.

Aos alunos será entregue um roteiro com os objetivos do experimento, competências, habilidades, a parte teórica, materiais necessários, o passo a passo da montagem, análise e observações que devem ser realizadas durante a execução da montagem.

Para incentivar a participação ativa dos alunos serão utilizados recursos educacionais em que os alunos sejam motivados a novas descobertas, e que participem do processo de ensino e aprendizagem de forma participativa.

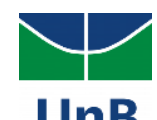


Para que outros professores possam utilizar o referido produto educacional, um breve manual será disponibilizado, informando os passos acima mencionados para que o professor possa trabalhar todas as etapas que fazem parte do produto.

Serão utilizados nesses experimentos, materiais de baixo custo, por exemplo, bases de madeira, seringas de diferentes diâmetros, dobradiças, parafusos, braçadeiras plásticas, mangueiras plásticas, corantes e ganchos.

\section{Resultados esperados e discussão}

O produto educacional será aplicado em sala de aula com alunos do segundo ano do Ensino Médio, da escola Estadual Aída Fíbiger de Oliveira no Município de Cacoal-RO, no segundo semestre de 2019.

Espera-se que com este estudo, a postura dos participantes/estudantes seja: participativa, demonstrando empenho na execução dos trabalhos em equipe, contribuindo com as discussões da classe sobre o tema em questão, respeitando as opiniões e concepções dos outros colegas.

\section{Agradecimentos}

À CAPES pela bolsa de estudos concedida, à UNIR e à SBF pela oportunidade de cursar o Mestrado Nacional Profissional em Ensino de Física.

\section{Conclusões}

O papel do professor nesse processo é o de facilitar o contato do aluno com a ciência, em que o aluno irá descobrir a relação desse conceito com o seu dia a dia, o produto educacional proporcionará que os alunos sejam capazes de compreender os conceitos dos fenômenos estudados, bem como relacioná-los com sua realidade, constatando em que situações da vida estão presentes os princípios abordados. A realização deste estudo trará como benefício uma produção teórica e empírica sobre o ensino de Física, ampliando a visão sobre Hidrostática e possibilitando ver as aplicações desse conteúdo na vida real.

O manual a ser utilizado em forma de histórias em quadrinhos proporcionará tanto aos professores quanto aos alunos e profissionais da área de Física, o acesso a uma forma mais dinâmica e interativa de tratar o tema de Hidrostática no ensino e aprendizagem da Física.

\section{Referências}

Ministério da Educação. PCNsEnsinoMédio, Orientações Educacionais Complementares aos Parâmetros Curriculares Nacionais:

Física.Brasília,2002.Disponívelem:<http://www.sbfisica.org.br/arquivos/PCN_FIS.pdf>. Acesso em: 31 ago. 2018.

FACOS/CNEC. Teoria Vigotskiana. Revista e-Ped - Vol. $2-\mathrm{N} \cong 1-$ Publicado em agosto de 2012. ISSN 2237-7077146. Disponível em: <http://facos.edu.br/publicacoes/revistas/e-ped/ago sto_2012/pdf/vygotsky_sua_teoria_e_a_influencia_na_educacao.Pdf>Acesso em: 24 out. 2018. MOREIRA, M. A. Teorias de Aprendizagem. São Paulo: Epu, 2009. 